Journal of

Dentistry and Oral Health

\title{
Analysis of Dimensional Standardization of Periodonal Probes: A Comparative Study
}

Antônio José Silva dos Santos ${ }^{2}$, Gabriel Gomes da Silva ${ }^{1}$, Everton Freitas de Morais ${ }^{1}$, Rafaella Bastos Leite ${ }^{1, *}$, Juliana Campos Pinheiro', Liane Maciel de Almeida Souza ${ }^{2}$, Eleonora de Oliveira Brandolin Martins ${ }^{3}$

${ }^{1}$ Federal University of Rio Grande do Norte-UFRN

${ }^{2}$ Federal University of Sergipe-UFS

${ }^{3}$ UNIT-Tiradentes University

${ }^{\star}$ Corresponding author: Dr. Rafaella Bastos Leite, Federal University of Rio Grande do Norte, Brazil, Tel: 83996218462; E-mail: rrafaella_bastos@hotmail.com

Received Date: September 18, 2019 Accepted Date: October 22, 2019 Published Date: October 24, 2019

Citation: Rafaella Bastos Leite (2019) Analysis of Dimensional Standardization of Periodonal Probes: A Comparative Study. J Dent Oral Health 6: 1-9.

\begin{abstract}
Periodontal probing is a clinical method for determining the diagnosis and treatment plan for Periodontics. The periodontal probe, the basic instrument of the exam, may present changes in the standardization of its intrinsic morphological parameters, thus leading to possible diagnostic errors and inadequate treatments. The present study examined 142 Golgran, Trinity and Millennium handheld WHO periodontal probes and 70 PCP-15 (North Carolina) Golgran and Millennium handheld periodontal probes used by students for periodontal diagnosis at a higher education in Aracaju-SE. All probes were analyzed with the aid of a $0.01 \mathrm{~mm}$ digital caliper. In the WHO probes, the cable diameter, the ball diameter, the diameter of the ball union with the active tip, the initial black stripe marking and the final black stripe marking were analyzed. In the PCP-15 probes, the diameter of the cable, diameter of the beginning of the millimeter marking, the diameter of the end of the millimeter marking, longitudinal millimeter markings of 0-5 mm, 0-10 mm and 0-15 mm were verified. The results showed that there is no uniform standardization between the marks, however, it can not be stated that the absence of standardization between the analyzed brands may influence the periodontal diagnosis, being necessary a further clinical study to observe if there is any kind of influence diagnosis and treatment.
\end{abstract}

Keywords: Probe; Periodontitis; Diagnosis

(C)2019 The Authors. Published by the JScholar under the terms of the Creative Commons Attribution License http://creativecommons.org/licenses/ by $/ 3.0 /$, which permits unrestricted use, provided the original author and source are credited. 


\section{Introduction}

The periodontium can be understood as the set of lining and support tissues of the teeth, represented as gum, periodontal ligament, root cementum, and alveolar bone $[1,2]$. The etiological factor determining the occurrence of changes in the periodontal structure is the accumulation of bacteria on the dental structure in the form of dental biofilm $[3,4]$.

The definition of health status or periodontal disease is based on a specific clinical examination, the clinical survey. Thus, the severity of the damage suffered by periodontal disease can be categorized based on the loss of clinical insertion and the depth of probing [2]. According to Nield-Gehri [5], the then eminent periodontist Orban already said that the periodontal probe is the "clinical eye below the gingival margin", that is, an essential instrument of a periodontal dental examination. It has other functions during a periodontal examination, such as: measuring gingival recessions, inserted gingival width, and intraoral lesions; assess the presence of gingival bleeding on probing and monitor the response of tissues to periodontal treatment [5].

Different manual periodontal probes with different calibrations and shapes are available on the national and international markets [4]. However, the use of a periodontal probe has its limitations, and probing measurements can be affected by several factors, such as probe-related including accuracy of marking intervals and probe thickness; related to the exam including probe angle, probing force, reference point accuracy and examiner experience [7].

However, the use of a periodontal probe has its limitations, and probing measurements can be affected by several factors, such as probe-related including accuracy of marking intervals and probe thickness; related to the exam including probe angle, probing force, reference point accuracy and examiner experience [8].

Thus, it can be said that intrinsic characteristics of the periodontal probe, when altered, such as weight, active tip diameter, millimeter markings, active tip sphere diameter, are capable of interfering with probing values, resulting in erroneous periodontal diagnoses. and inadequate treatment plans $[9,10]$.

According to WHO (1990) the periodontal probe, which is said to be ideal for community periodontal examinations such as the Community Periodontal Index of Treatment Needs (CPITN), should have some standardized characteristics, so as to avoid the maximum number of distortions during the examinations [7]. Among these characteristics it can be said that: a) The probe had cable with diameter of $3,5 \mathrm{~mm}$ and maximum weight of 4,5g; (b) The longitudinal millimeter markings of the probe shall be correct; c) The diameter between the union of the ball and the active tip shall be $0,30 \mathrm{~mm}$; d) The ball contained at the end of the active probe tip must be $0.5 \mathrm{~mm}$ in diameter or thickness [11].

Even scarce in the current literature, some authors concerned about the repercussions of non-standardization of periodontal probes sought to conduct research to evaluate these dimensional changes of the most commonly used periodontal probes in the dental environment [12]. It is confirmed that the specific literature that evaluates the morphological characteristics of periodontal probes is still scarce, so there is still a lack of this type of investigation [11].

Given the above, the objective of this study was to analyze the morphological characteristics of periodontal probes used for periodontal diagnosis in the Dental Clinics of Tiradentes University (UNIT) in 2015/1. Being evaluated the different types of characteristics presented in the structure of periodontal probes. The WHO probes (following the 1990 WHO recommendations) were analyzed: Cable diameter (DC); Sphere diameter (ED); Diameter of the union between the ball and the active tip (DU); Initial longitudinal linear marking of the black stripe (MI); Linear longitudinal end mark of the black stripe (MF). The PCP-15 probes (North Carolina probe) were analyzed: Cable diameter (DC); Diameter of beginning of millimeter tip (DIP); Diameter of end of millimeter tip (DFP); Longitudinal marking from 0 to $5 \mathrm{~mm}$ (M1); Longitudinal marking from 0 to $10 \mathrm{~mm}$ (M2); Longitudinal marking from 0 to $15 \mathrm{~mm}$ (M3).

\section{Materials and Methods}

The sample evaluated in the present study consisted of: 142 WHO periodontal probes of the Golgran ${ }^{\oplus}$ brands (Golgran Industry and Trade Dental Instruments Ltda., Sao Caetano do Sul-SP) $(n=52)$, Trinity ${ }^{\circledast}$ (Trinity Industry and Comércio Ltda., Jaraguá-SP) $(\mathrm{n}=16)$ and Millennium ${ }^{\circledR}$ (Golgran Industry and Trade of Dental Instruments Ltda., São Caetano do Sul-SP) (n = 74); 70 PCP-15 (North Carolina) periodontal probes of the Golgran $^{\circledR}$ (Golgran Industry and Trade Instruments), São Caetano do Sul-SP $(\mathrm{n}=8)$ and Millennium ${ }^{\varpi}$ (Golgran Industry and Trade Instruments) brands Dentistry Ltda., Sao Caetano do Sul-SP) (n $=62$ ). For this study, opt for the non-probabilistic convenience sampling method for the purpose of analyzing all probes available only among the students analyzed. 
All probes belonged to regular students, enrolled in the first semester of 2015, who were attending or who had already attended the Periodontics course at Tiradentes University (UNIT). New and used periodontal probes were considered within the study, except for those with defects such as active tip fracture, discoloration in their markings, or any other damage that made reading difficult during the analysis process.

The probes were always evaluated by a single examiner and the measurement was made by means of a four-digit digital caliper (Digimess 100.174BL, Digimess Precision Instruments Ltda. São Paulo - SP) (Figure 1) with an accuracy of $0.01 \mathrm{~mm}$. It is considered more accurate than the analog caliper. Throughout the research process, the researcher was responsible for the safekeeping of the objects and any damage or damage caused by it to the probes would be completely assumed by the researcher. The probes included were divided according to their type and trademarks.

Probes were always evaluated by a single examiner. When under analysis, the probe was held with the hands of the examiner who stood with his arms propped on a firm, flat surface bench to prevent slippage and position changes that could interfere with the analysis of the dimensional variables of the probe (Figure 2). The only item evaluated where this methodology was not applied was for the analysis of the cable diameter of the periodontal probes. In this case, the researcher placed the probe perpendicular to the ground and with the caliper claws held the probe by the hexagon (Figure 3).

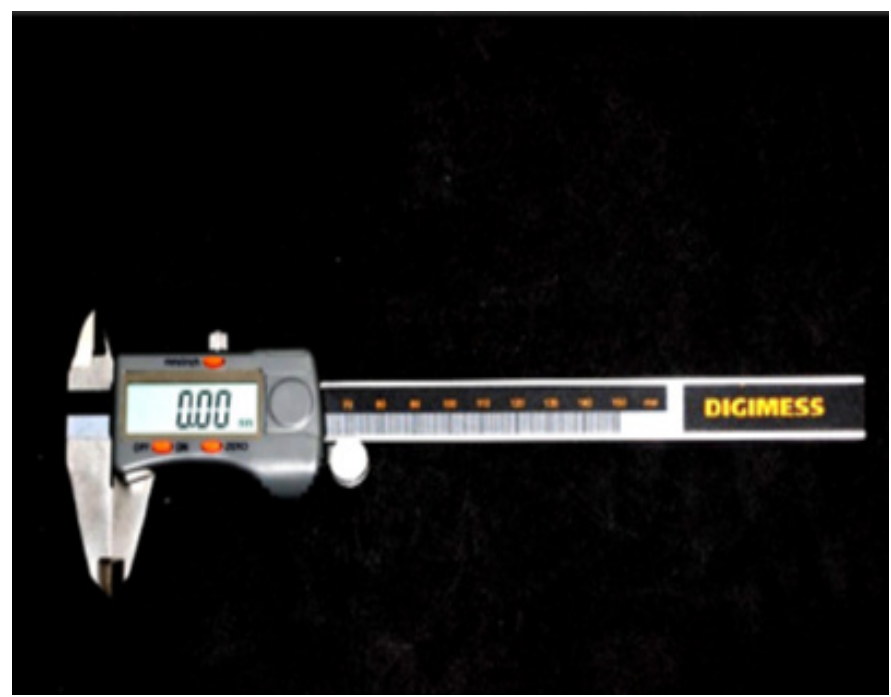

Figure 1 - Four digit digital caliper (Digimess 100.174BL, Digimess Precision Instruments Ltda. Sao Paulo - SP)

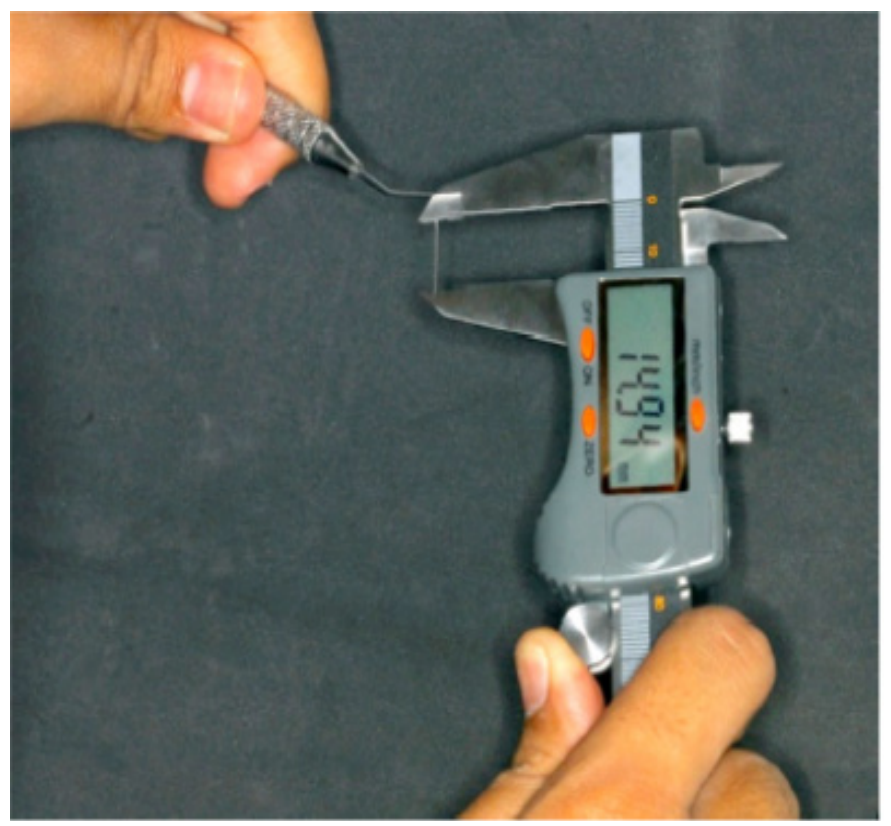

Figure 2 - Measurement of a PCP-15 type probe in the 0.015.0 $\mathrm{mm}$ marking parameter, according to the adopted methodology.

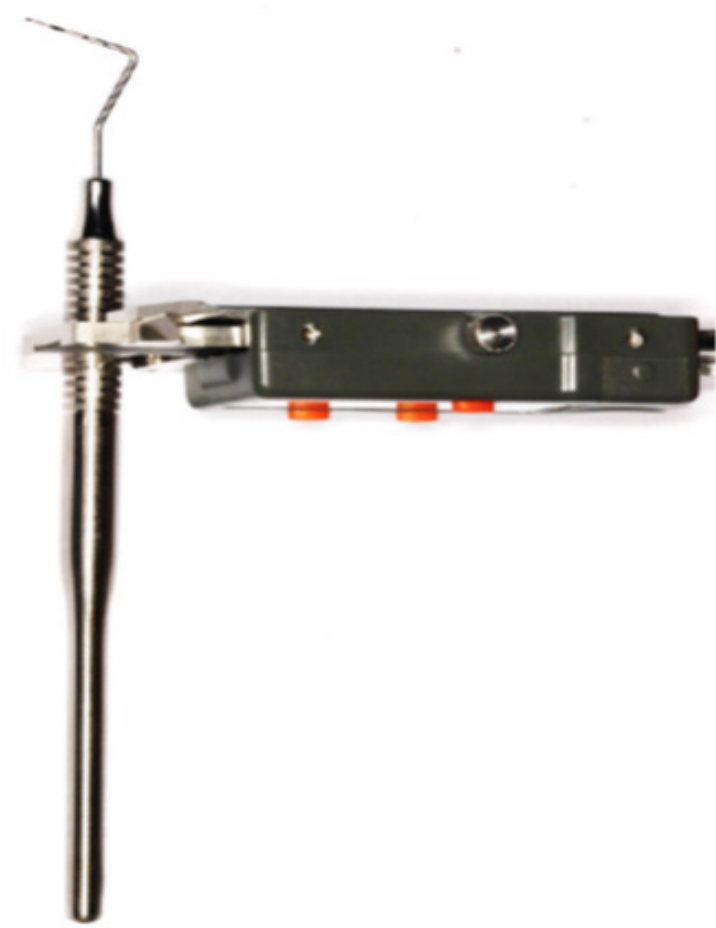

Figure 3 - WHO periodontal probe perpendicular to the ground under cable diameter analysis (lateral view). 
The collected data (mean and standard deviation) was then taken to the Bioestat 5.0 program for statistical analysis by applying the $t$-Student test with a significance level of $99 \%$ ( $p$ $<0.001)$. For each characteristic analyzed, three measurements were performed to obtain arithmetic means and standard deviations. These means were summed and again obtained means and standard deviations. In this way, an understanding of the dimensional behavior of the evaluated instruments is sought. The data collected (means and standard deviations) were tabulated in a Microsoft Excel spreadsheet.

\section{Results}

Table 1 express the means and standard deviations found in the WHO probes ( $\mathrm{n}=142)$ of all brands surveyed without distinction by brands compared to the means recommended by WHO. According to WHO standards: cable diameter should be $3.5 \pm 0.2 \mathrm{~mm}$; the diameter of the sphere $0,5 \pm 0,1 \mathrm{~mm}$; the diameter of the union between the ball and the tip $0.3 \pm 0.05$ $\mathrm{mm}$; the linear longitudinal initial marking of the black stripe $3,5 \pm 0,1 \mathrm{~mm}$ and the linear longitudinal marking of the black stripe $5,5 \pm 0,1 \mathrm{~mm}$. In the analysis, only the initial and final markings of the black stripe are, on average, according to WHO standards. The other items presented a variation higher than the recommended, emphasizing that the cable diameter presented a great difference to the one initially recommended by the WHO.

Graph 2 and Table 2 show the means and standard deviations found in the WHO periodontal probes by trademarks: Golgran $(n=52)$, Trinity $(n=16)$ and Millennium $(n=74)$.

\begin{tabular}{|l|l|l|l|l|l|}
\hline & DC & DE & DU & MI & MF \\
\hline Standard & $3,50 \pm 0,20$ & $0,50 \pm 0,10$ & $0,46 \pm 0,08$ & $3,50 \pm 0,10$ & $5,50 \pm 0,10$ \\
\hline $\begin{array}{l}\text { Average General } \\
(\mathrm{n}=142)\end{array}$ & $6,00 \pm 1,77$ & $0,61 \pm 0,10$ & $0,46 \pm 0,08$ & $3,54 \pm 0,18$ & $5,58 \pm 0,14$ \\
\hline
\end{tabular}

Table 1 - Averages and Standard Deviations found in all periodontal probes without brand distinction researched $(n=142)$. DC: Cable Diameter; DE: ball diameter; DU: Diameter of ball union with active tip; MI: Initial marking of the black stripe; ME: Final marking of the black stripe.

\begin{tabular}{|l|l|l|l|l|l|}
\hline Brands & DC & DE & DU & MI & MF \\
\hline Standard & $3,50 \pm 0,20$ & $0,50 \pm 0,10$ & $0,46 \pm 0,08$ & $3,50 \pm 0,10$ & $5,50 \pm 0,10$ \\
\hline Golgran & $4,24 \pm 0,08$ & $0,65 \pm 0,07$ & $0,49 \pm 0,67$ & $3,55 \pm 0,14$ & $5,56 \pm 0,13$ \\
\hline Trinity & $4,14 \pm 0,16$ & $0,46 \pm 0,14$ & $0,34 \pm 0,04$ & $3,49 \pm 0,25$ & $5,58 \pm 0,22$ \\
\hline Millennium & $7,65 \pm 0,61$ & $0,62 \pm 0,06$ & $0,47 \pm 0,07$ & $3,54 \pm 0,18$ & $5,59 \pm 0,13$ \\
\hline
\end{tabular}

Table 2 - Averages and Standard Deviations found in WHO periodontal probes by trademark, in an intra-brand and inter-brand comparison. DC: Cable Diameter; DE: ball diameter; DU: Diameter of ball union with active tip; MI: Initial marking of the black stripe; ME: Final marking of the black stripe. 


\section{WHO probe size by trademark}

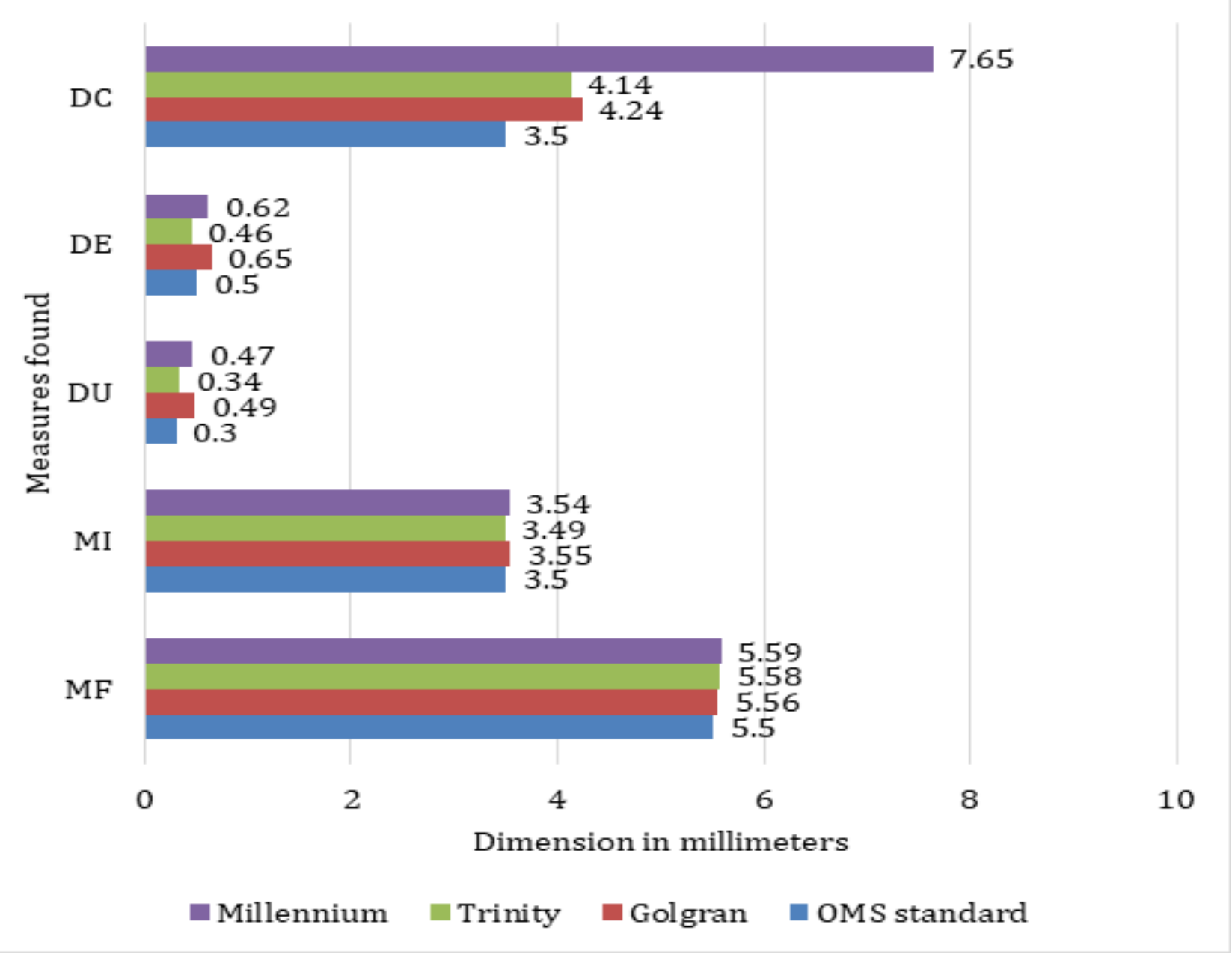

Graph 2 - Comparison between the averages found of the different brands of WHO periodontal probes surveyed with the WHO standard. DC: Cable Diameter; DE: ball diameter; DU: Diameter of ball union with active tip; MI: Initial marking of the black stripe; ME: Final marking of the black stripe.

Cable diameter was the characteristic that varied the most in the study between brands, due to the different manufacturing standards used in each trademark. Golgran and Trinity probes have a smaller cable thickness when compared to Millennium. Regarding the diameter of the sphere, only the Trinity brand achieved on average the values recommended by WHO for this parameter. The Golgran and Millennium probes were, on average, thicker than recommended. The values of the diameter of the union between the sphere and the active tip showed that the greater the thickness of the active tip sphere of the WHO periodontal probe, the larger this diameter will be. Thus, it is evident that the Golgran and Millennium brands had the largest diameter when compared to the Trinity brand. In the research, it was elucidated that all brands researched have longitudinal markings of black stripe within the standards recommended by WHO.

Table 3 shows the means and standard deviations found in the analysis of periodontal probes of type PCP-15 ( $n=70)$ of all trademarks surveyed. For the analysis of the linear longitudinal markings of the PCP-15 probes, this research used the variants allowed by the WHO ( $\pm 0.1 \mathrm{~mm}$ of linear deviation). In a general analysis, all longitudinal marking requirements have been shown to be standardized.

Table 4 shows the means and standard deviations found in the analysis of PCP-15 periodontal probes separated by trademarks: Golgran $(n=8)$ and Millennium $(n=62)$. In an evaluation between the marks, it is observed that both present the beginning and end diameter of the similar millimeter marking. However, the diameter of the cable is noticeable between brands, where Millennium obtained larger diameter due to its manufacture with hollow cable and more caliber. As for the linear markings, it is observed that Millennium was within the standards and Golgran evaded the standards. 


\begin{tabular}{|l|l|l|l|l|l|l|}
\hline & DC & DI & DU & M1 & M2 & M3 \\
\hline Average & 7,39 & 0,52 & 1,01 & 5,01 & 9,94 & 15,00 \\
\hline Detour standard & 1,13 & 0,06 & 0,04 & 0,18 & 0,14 & 0,13 \\
\hline
\end{tabular}

Table 3 - Means and standard deviations found in all periodontal probes of type PCP-15 surveyed $(n=70)$. DC: Cable Diameter; ID: Diameter of the start of millimeter marking; DU: Diameter of end of millimeter marking; M1: 0-5 mm longitudinal millimeter markings, M2: 0-10 mm longitudinal millimeter markings; M3: Millimeter longitudinal markings of $0-15 \mathrm{~mm}$.

\begin{tabular}{|l|l|l|l|l|l|l|}
\hline & DC & DI & DF & M1 & M2 & M3 \\
\hline Golgran & $4,27 \pm 0,10$ & $0,68 \pm 0,09$ & $0,93 \pm 0,05$ & $4,63 \pm 0,21$ & $9,67 \pm 0,10$ & $14,84 \pm 0,22$ \\
\hline Millennium & $7,80 \pm 0,11$ & $0,5 \pm 0,45$ & $1,02 \pm 0,03$ & $5,06 \pm 0,11$ & $9,97 \pm 0,07$ & $15,02 \pm 0,10$ \\
\hline
\end{tabular}

Table 4 - Means and Standard Deviations found in PCP-15 periodontal probes by trademark, in an intra-brand and inter-brand comparison. DC: Cable Diameter; ID: Diameter of the start of millimeter marking; DU: Diameter of end of millimeter marking; M1: 0-5 mm longitudinal millimeter markings, M2: 0-10 mm longitudinal millimeter markings; M3: Millimeter longitudinal markings of 0-15 mm.

\section{Discussion}

The periodontal probe is a slim instrument, has millimeter markers like a ruler. The active part of the instrument is blunt, straight and generally tapered [6]. The tip of the active part is usually rounded in cross-section but can be flat or rectangular depending on the type of probe. At the junction of the rod with the active part, the end rod is curved and the active part is at approximately right angles [5]. The rest of the rod is straight or offset to facilitate the fitting of the probe to all areas of the mouth [16].

According to Schoen and Dean [17], several probes have been modified to increase their clinical diagnostic capacity. This is the case of the WHO type periodontal probe, which had its blunt end of the active part replaced by a sphere of approximately $0.5 \mathrm{~mm}$, according to $\mathrm{WHO}$ recommendations. The main purpose of this exchange was to increase the clinician's tactile sense in the act of probing.

Schoen and Dean [17] determined the proper technique for using any periodontal probe. The technique itself is to hold the probe with a modified pen grip with light pressure [16]. The use of gentle grip and pressure increases the clinician's tactile sensitivity and allows us to determine when the junctional epithelium is reached 16. Excessive pressure can cause trauma and patient discomfort. In a healthy person, the probe stops at the junctional epithelium (probing depth) [15]. When the tissue is inflamed, the tube often passes through the ulcerated junctional epithelium and comes into contact with the underlying connective tissue [15].

Thus, it was established that one of the most viable and practical forms of periodontal diagnosis is the rational use of the periodontal probe, regardless of type. However, studies indicate that the act of probing suffers influences that alter the reliability of the instrument used $[8,9,18,19,20,21]$. Periodontal probing when erroneous can result in also inadequate periodontal diagnoses [20]. As a result, the patient may be exposed to the course of inappropriate treatment, potentially exposing them to iatrogenic trauma on some occasions [9]. The present study verified the standardization of periodontal probes $[2,5]$.

Rapp [13] stated that the essential characteristics of the WHO-approved periodontal probe are to allow better operator tactile acuity at the time of probing, in addition to being safer without causing damage to periodontal tissues [13]. Regarding the cable diameter or thickness of the periodontal probes, regardless of the type (WHO or PCP-15) or brands searched (Golgran, Trinity and Millennium), there is no current research showing an evaluation of this question of probes, in general analysis and between brands available in the domestic and international markets [14]. The results of this research showed that this same feature is the most neglected, as they do not have a definite pattern. Golgran presented on average $4.24 \mathrm{~mm}$ of cable, Trinity in turn $4.14 \mathrm{~mm}$ and Millennium $7.65 \mathrm{~mm}$.

The WHO [11] in 1990 determined that cable diameters should be $3.5 \mathrm{~mm}$ with a range of $0.2 \mathrm{~mm}$ plus and a range of $0.1 \mathrm{~mm}$ minus [11]. Which clinically reproduces a cable with a 
thinner thickness. Contrary to this, it can be affirmed that cables of thicker thickness are better clinically, whereas cables of smaller thickness tend to bring interference to the clinical operator, such as verifying the presence or absence of subgingival calculus, for example [8].

Compared to the research by Neto [19], both surveys follow a similar methodological approach, which is to evaluate the parameters of the probe with a caliper. However, ours used a digital caliper and a sample of $142 \mathrm{WHO}$ probes and 70 PCP15 probes and the other used an analog caliper and a sample of 32 WHO probes and 26 PCP-15 probes. For Rocco [14], digital calipers, in general, have a higher accuracy when compared to analog calipers. The margin of error for digital calipers is smaller, which tends for more realistic results for a statistical evaluation [13].

The results obtained from the verification of Neto [19] showed that the diameter or thickness of the tip of the WHO probes was, in general, $0.83 \mathrm{~mm}$, a result different from what our research found $(0.69 \mathrm{~mm})$. In the study between brands for the same parameter, the brands Golgran and Millennium did not show the similarity between the two surveys [18]. While our data showed, on average, Golgran $(0.65 \mathrm{~mm})$ and Millennium $(0.62 \mathrm{~mm})$, the findings of the other survey mentioned above show that Golgran averaged $0.91 \mathrm{~mm}$ and Millennium $0.79 \mathrm{~mm}$ When the initial and final markings of the black stripe are compared between the two surveys, what can be seen is that there is a consonance of values, within the allowed range of $0.1 \mathrm{~mm}$, in overview and in the mark Millennium and Golgranand value disagreement, greater variation of $0.1 \mathrm{~mm}$, only in the Golgran final marking requirement. In a general analysis of the probes, independent of brand, the results of the past survey were 3.58 $\mathrm{mm}$ and $5.54 \mathrm{~mm}$, while ours for the same parameters were $(3.54$ $\mathrm{mm})$ and $(5.58 \mathrm{~mm})$. The results for the Millennium probe were $(3.54 \mathrm{~mm})$ and $(5.59 \mathrm{~mm})$, while his were $3.61 \mathrm{~mm}$ and $5.65 \mathrm{~mm}$. For the Golgran brand probes, ours point on average $(3.55 \mathrm{~mm}$ ) and $(5.56 \mathrm{~mm})$, while theirs show $3.55 \mathrm{~mm}$ and 5.43 .

Rapp [13] conducted a survey in the mid-2000s in which they checked the Trinity-branded WHO probes. One hundred (100) new probes were measured in the following characteristics: tip ball diameter, as well as initial and final reference of the colored band, by indirect morphometric method, and weight, with the aid of precision balance [14]. The results for each parameter of Trinity brand WHO probes were on average: $0.54 \mathrm{~mm}$ for ball diameter; initial marking of the colored band at 3.56 and ending at $5.76 \mathrm{~mm} 13$. When comparing the results found in our evalu- ation of the same characteristics of the Trinity probes, there is a consonance, within the allowed range of $0.1 \mathrm{~mm}$, in the sphere diameter $(0.46 \mathrm{~mm})$ and initial color band marking. (3.49 $\mathrm{mm})$ and a discrepancy, greater than $0.1 \mathrm{~mm}$ variation, from the values, found for the final marking of the colored band $(5.58 \mathrm{~mm})$.

Within our results for WHO probes, the Trinity trademark was the one that behaved the most, within WHO standards. The only feature outside the international standards of excellence to be modified is the diameter of the probe cable [17]. The other results of this research, for the analysis of the PCP-15 probes, are in line with most studies evaluating different periodontal probes, both nationally and internationally, regarding the lack of standardization of the dimensional and physical parameters of periodontal probes, when equal parameters of any type of probe are evaluated within and between the brands $[8,9,18]$.

From our results for the PCP-15 probes, the Millennium trademark was the one with the best averages and variations for millimeter markings. Van der Zee, Davies, Newman [2, 20] proposed a survey that evaluated the standardization of the seven most commonly used probe types at the time, namely: WHO, Williams, and Michigan. The stereomicroscope with 40x magnification had been used to evaluate the thickness at different active tip markings, the accuracy of the millimeter markings and the diameter of the outer parts of the active tip [14]. In all these parameters there were significant variations. What can be observed after conducting this research was that the results found in it are similar to other studies already conducted, regarding the averages and standard deviations of the WHO Probe. According to them, the standardization of active tips could increase the accuracy and reproducibility of measurements without depending on any type of probe and / or brand [20].

Using an image analyzer and a digital caliper, César [21] evaluated the measurements of the 1st, $2 \mathrm{nd}, 3 \mathrm{rd}, 5 \mathrm{th}, 7 \mathrm{th}$ and 10th of 94 Williams type periodontal probes of the Neumar/Brasil $^{\oplus}$, Golgran/Brasil ${ }^{\oplus}$ and Hu-Friedy/USA ${ }^{\oplus}$ brands, concluding that $\mathrm{Hu}$-Friedy / USA ${ }^{\circledast}$ presented more accurate measurements, coming very close to the standard measurements and showing little variation among the sample elements [21].

Penteado [18] searched in 103 active tips of 56 Williams or modified Williams periodontal probes [18]. The research used a digital caliper to analyze the diameter of the sphere and the tip, millimeter markings, and the weight of the probes by means of a two-digit digital precision scale. In the end, they concluded that there was no standardization of weight parameters, ball, and active tip diameters, as well as the millimeter markings [18]. 


\section{Conclusion}

Given the results obtained and respecting the methodology adopted, it is concluded that for the cable diameter parameter of the WHO probes, there is no standardization between the brands, and the results of the Millennium trademark have a better clinical application because of its cable. be, on average, more unctuous. Regarding the sphere diameter parameter of the WHO probes, only the Trinity brand probes were within the standards recommended by the WHO. As far as the parameter of the union diameter between the sphere and the active tip of the WHO probes is concerned, only the Trinity mark was within the WHO parameters. The initial linear longitudinal black stripe marking parameter of the WHO type probes, all brands searched are in accordance with WHO.

For the longitudinal black stripe marking parameter of the WHO type probes, all brands searched are in accordance with WHO. Regarding the cable diameter parameter of the PCP-15 probes, there was no standardization and similarity between the two trademarks, as well as the diameter parameter of the beginning of the millimeter tip of the PCP-15 probes, both brands show the similarity between their results. Regarding the millimeter marking parameter of 0.0-5.0 mm, only the Millennium mark was within the standards. Regarding the millimeter marking parameter of 0.0-10.0 mm, only the Millennium mark was within the expected standards, and when observed the millimeter marking parameter of $0.0-10.0 \mathrm{~mm}$, only the Millennium brand also confirmed the expected commercial standards. Therefore, it is suggested that further research be done to aim for a gold standard of excellence for any type of manual periodontal probe, both nationally and internationally manufactured. Thus, periodontal examinations may be more realistic and the most appropriate treatment plan.

\section{References}

1. Lindhe J, et al. (2005) Treaty of Clinical Periodontics and Oral Implantology. 4. ed. Rio de Janeiro: Guanabara Koogan.

2. Newman MG, et al. (2012) Carranza Clinical Periodontics. 11. ed. Rio de Janeiro: Elsevier.

3. Hirschfeld L A (1953) Calibrated silver point for periodontal diagnosis and recording. J Periodontol 24:94.

4. Kinane DF, et al. (2001) Periodontal manifestations of systemic disease. Aus Den J. 46: 2-12.

5. Nield-Gehrig JS (2013) Fundamentals of Periodontal Instrumentation and Advanced Root Instrumentation. 7. ed. Philadelphia: Lippincott Williams \& Wilkins.

6. Pinto FM, et al. (2009) Clinical survey of the gingival sulcus: evaluation of its variability and reproducibility. RGO. 54: 39-42.

7.Holtfreter B, et al. (2012) Effects of different manual periodontal probes on periodontal measurements. J. Clin. Periodontol 39: 1032-1041.

8. Costa RCC, et al. (2007) Conventional Periodontal Probes: A Review. Rev. ABO Nat 15: 296-299.

9. Drucker SC, et al. (2012) Periodontal Probing Calibration in an Academic Setting. Journal of Dental Education 76: 1466-1472.

10. Nassar CA, Nassar PO, Pedrotti S, et al. (2014) Evaluation of different brushing techniques in patients with cardiovascular disease with periodontal disease - pilot study. Arch Catarin Med. Apr-Jun 43: 36-43.

11.Shiau HJ, Aichelmann-Reidy ME, Reynolds MA (2014) Influence of sex steroids on inflammation and bone metabolism. Periodontol 2000. 64: 81-94.

12. Williams RC, Paquette DW (2010) Periodontal Disease as a Risk for Systemic Disease. In: Lindhe J, Lang NP, Karring T. Treatise on Clinical Periodontics and Oral Implantology. Rio de Janeiro: Ed. Guanabara Koogan 460-465.

13. Gupta S, Jain A, Mohan S, Bhaskar N, Walia PK (2015) Comparative evaluation of oral health knowledge, practices, and at- 
titude of pregnant and non-pregnant women, and their awareness regarding adverse pregnancy outcomes. J Clin Diagn Res. 9: ZC26-32.

14. Fardini Y, Chung P, Dumm R, Joshi N, Han YW (2010) Transmission of diverse oral bacteria to murine placenta: evidence for the oral microbioma as a potential source of intrauterine infection. InfectImmun 78: 1789-1796.

15. Passanezi E, et al. Periodontal biological bases. Chapter 2. In: Passanezi E. et al. Periodontal Biological Distances: principles for periodontal, aesthetic and prosthetic reconstruction. São Paulo: Medical Arts, p.22-53, 2011.

16. Ramachandra SS, et al. (2011) Periodontal Probing Systems: A Review of Available Equipment. Compendium of Continuing Education in Dentistry 32: 71-77.

17. Schoen DH, et al. (1997) Instrumentation in contemporary periodontics. Sao Paulo. Santos 242.

18. Hairstyle LAM, et al. (2010) Dimensional changes of williams type periodontal probes submitted to 100 autoclaving cycles. Rev. Periodontics 20: 75-81.

19. Grandson JMA (2014) Evaluation of the standardization of periodontal probes of a higher education institution in AracajuSE. Completion of course work. (Degree in Dentistry) AracajuSE: Tiradentes University.

20. Junior CRM (2010) The influences of periodontal condition in the pregnant woman. Planalto Central Dental Journal 1: 1520.

21. Moreira CHC (2009) Periodontal diseases in pregnancy: clinical course and treatment response [Doctoral Thesis] - Postgraduate Program in Dentistry, Porto Alegre: Federal University Of Rio Grande Do Sul.

Submit your manuscript to a JScholar journal and benefit from:

9 Convenient online submission

ब Rigorous peer review

I Immediate publication on acceptance

ๆ Open access: articles freely available online

ब High visibility within the field

- Better discount for your subsequent articles

Submit your manuscript at http://www.jscholaronline.org/submit-manuscript.php 